\title{
PHYSIOLOGICAL APPARATUS IN THE WELLCOME MUSEUM 1. THE MAREY SPHYGMOGRAPH
}

\author{
by
}

\section{CHRISTOPHER LAWRENCE*}

ONE CHARACTERISTIC of the new physiology of the nineteenth century was the graphic representation of body function. ${ }^{1}$ It provided a means whereby transient phenomena could be translated into a permanent record and studied at leisure. The dynamics of the cardiovascular system were particularly susceptible to such techniques. In 1860 E. J. Marey (1830-1904) devised the first convenient sphygmograph for graphically recording the pulse wave. It received an enthusiastic reception from a small number of clinicians in Great Britain. Though several other models later supplanted it, Marey's original design remained popular throughout the latter half of the nineteenth century. The Wellcome Museum** contains seven sphygmographs of the Marey type (see Appendix). Through these it is possible to trace the technical modifications of the instrument and in turn to make wider comment on the significance of instrumentation in nineteenth-century physiology and medicine.

Such an apparently simple physiological tool as graphic representation has a long and complex history, the origins of which ultimately lie in the development of ballistics. ${ }^{2}$ Attempts to demonstrate the dynamics of the vascular system, on the other hand, go back only to the early eighteenth century and the Haemostaticks of Stephen Hales. ${ }^{3}$ Hales cannulated the femoral artery of a horse with a glass tube and observed the height of the blood pressure. His experiments, unique

*Christopher Lawrence, M.B., Ch.B., M.Sc., Medical Historian to the Wellcome Museum at the Science Museum, South Kensington, London SW7 2DD.

**The Museum of the Wellcome Institute for the History of Medicine is currently being transferred to the Science Museum, South Kensington, London, on indefinite loan, where it will form the Wellcome Museum of the History of Medicine.

${ }^{1}$ For a general account of nineteenth-century physiological technology see: Kenneth D. Keele, The evolution of clinical methods in medicine, London, Pitman, 1963.

On the graphic method see: Hebbel E. Hoff and L. A. Geddes, 'A historical perspective on physiological monitoring: Sherrington's mammalian laboratory and its antecedents', Cardiovasc. Res. Cent. Bull. (Baylor Univ.), 1974, 13: 19-39. Hebbel E. Hoff and L. A. Geddes, 'A historical perspective on physiological monitoring: Chauveau's projecting kymograph, and the projecting physiograph', ibid., 1975, 14: 3-35.

' Hebbel E. Hoff and L. A. Geddes, 'The technological background of physiological discovery: ballistics and the graphic method', J. Hist. Med., 1960, 15: 345-363.

Stephen Hales, Statical Essays, Vol. 2, Haemastaticks, London, W. Innys \& Marby, 1738. There is in fact a sixteenth-century account of the quantitative estimation of the hardness of the pulse. See A. Schott 'An early account of blood pressure measurement by Joseph Struthius (1510 1568)', Med. Hist., 1977, 21 : 305-309. 


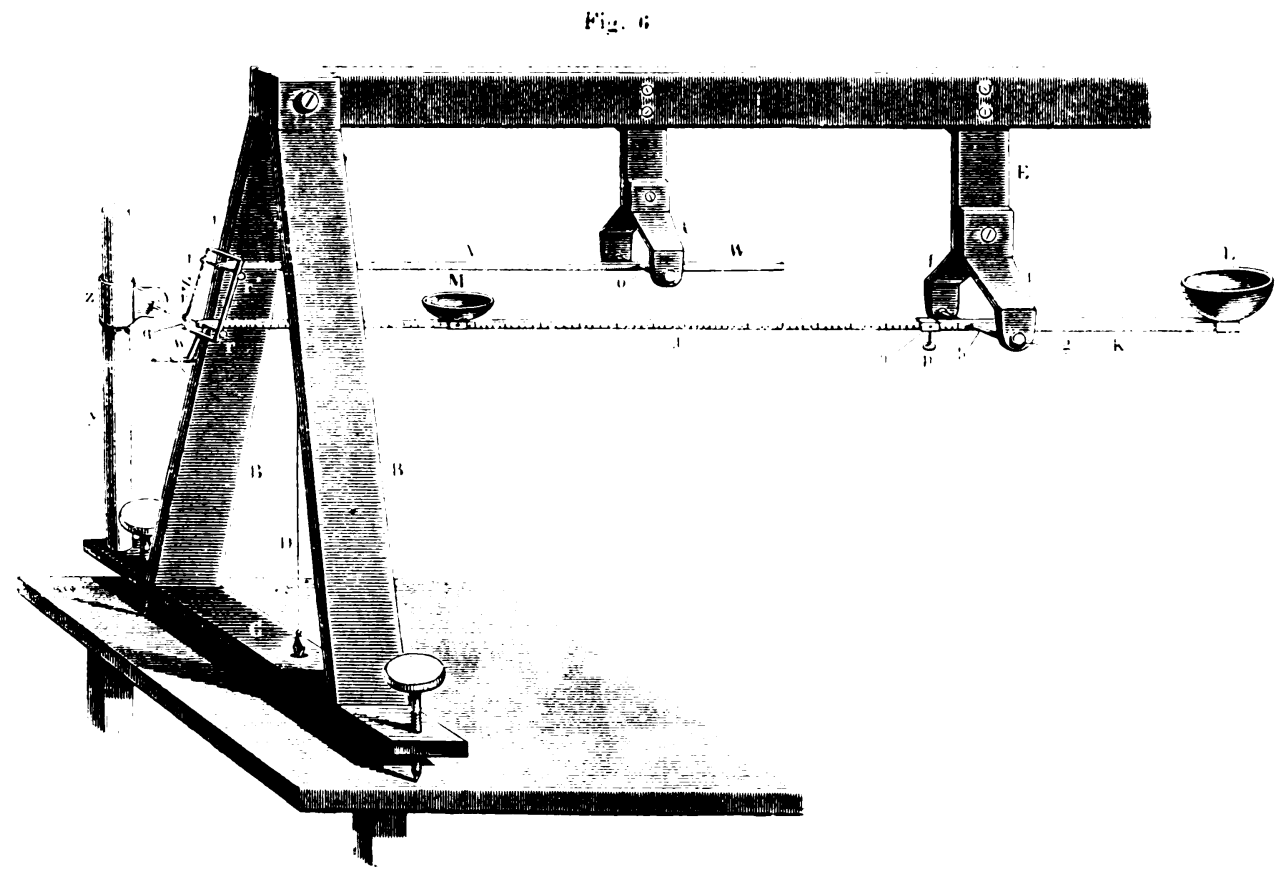

Figure 1.

Vierordt's original sphygmograph. From Karl Vierordt, Die Lehre vom Arterienpuls, Braunschweig, F. Vieweg, 1855, p. 22.

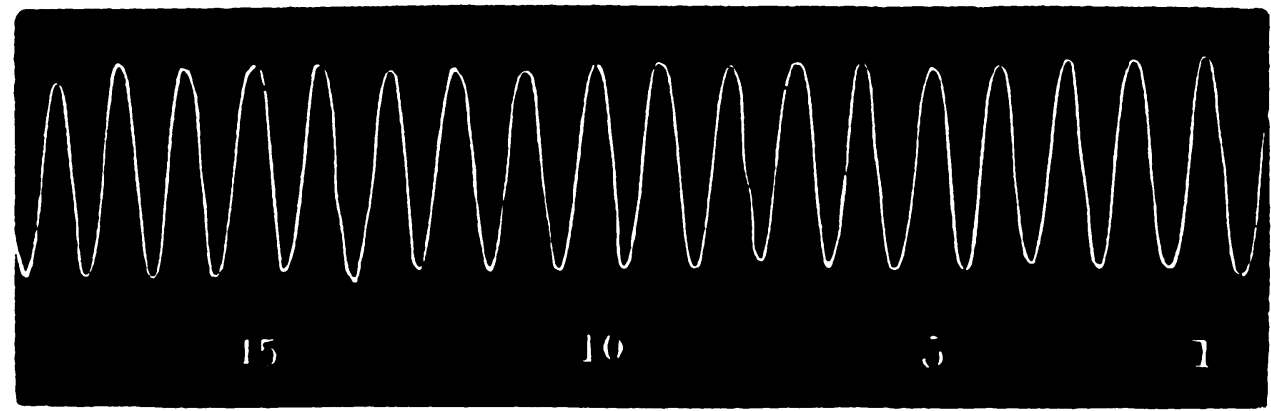

lig. 21.

Figure 2.

Pulse curve taken with Vierordt's sphygmograph. From É. J. Marey, Physiologie médicale de la circulation du sang, Paris, Adrien Delahaye, 1863, p. 176. 


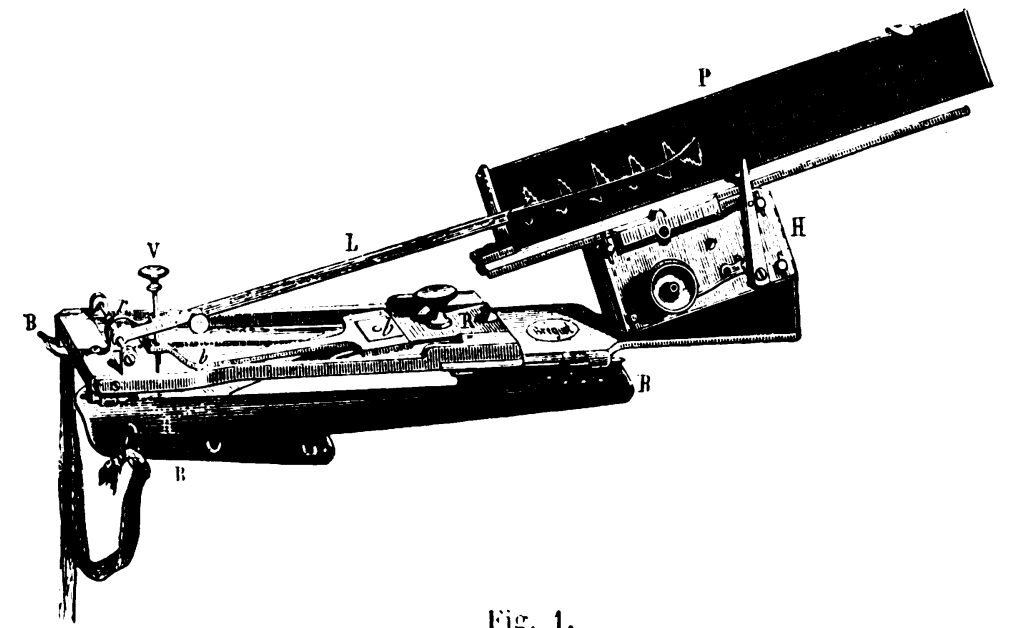

Figure 3.

Marey's original illustration. The makers' name, Breguet, is clearly visible. From É. J. Marey, 'Recherches sur l'état de la circulation d'après les caractères du pouls fournis par le nouveau sphygmographe', J. Physiol. homme animaux, 1860, 3: p. 244.

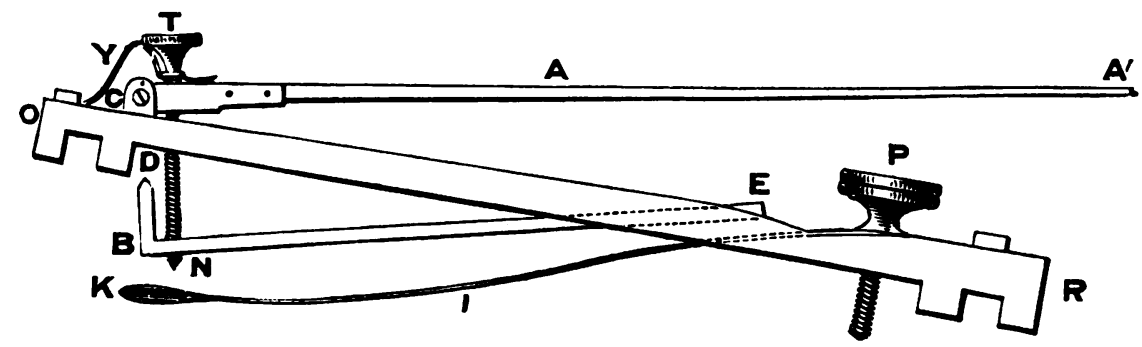

Figure 4.

The interior of the Marey sphygmograph. From J. Burdon-Sanderson, Handbook of the sphygmograph London, Robert Hardwicke, 1865, frontispiece. 


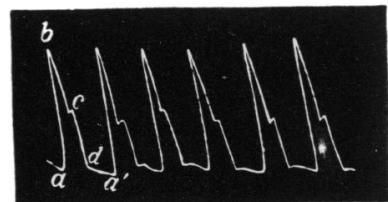

F10. 11.-Pressure, $2 \ddagger 0 z$.

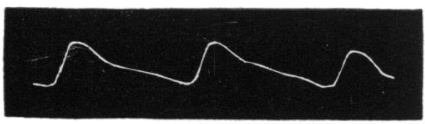

Fig. 13.-Pressure, $1 \frac{1}{2}$ oz.

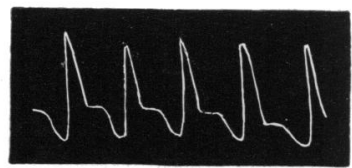

FI(i. 15.-Pressurt, $20 \mathrm{z}$.

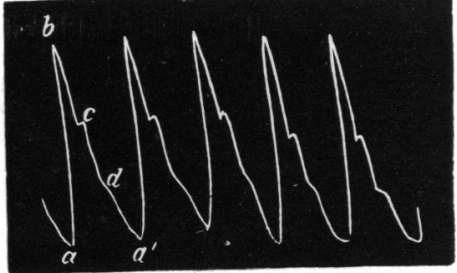

Fig. 12.-Fressure, 3 oz

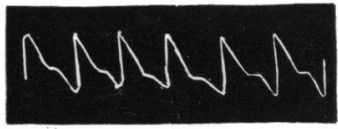

Fif. 14.-Pressure, 3 о7..

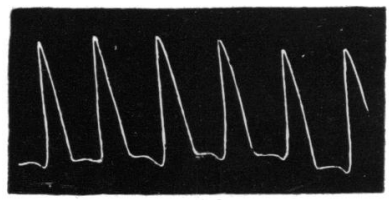

Fir. 16.-Pressure, 21 oz.

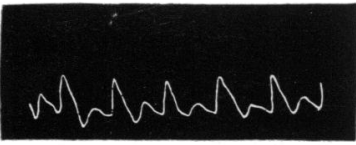

Fli. 17.-Pressure, 3 oz.

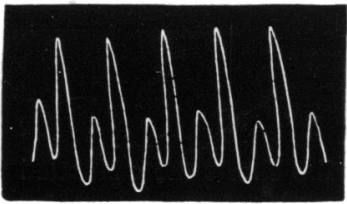

Fui. 1S.-Pressure, $3 \mathrm{nz}$.

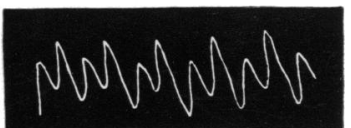

Fig. 19.-l'ressure, 407.

\section{INESCRIPTION OF FI(; ERES.}

Fı. 11.-Antic Regurgitntion.-Case: G. A., : at. 56, admitted tn Newcastle Infirmary under Dr Byrom Bramwell, 21 st February 1878. suffering from shortness of breath and swelling of fowt. llad been ill for three months. The face was pale and anxious, lips slightly dusky. Double aortic murmur; heart considerably hypertrophied: npex between 6 th and 7 th ribs, 3 inches below and 2 inches outside left nipple. Considerable hypertrophy and engorgement of right heart. Died 5th March 1879. Aorta very atherumatous; antic valves very incompetent; segments shrunken, turned in towards the ventricle; coronary arteries much obstructed; cardiac walls fatty; left ventricle dilated; pericardium adherent. The arteries were practically empty during carliac diastole. $a-l=$ percussion stroke; $b==$ apex; $c=$ tidal wave; $l$ indicates the position of the aortic wave, which is absent in this tracing.

Fı. 12.-Antic Regurgitation.-Taken from same patient as No. 11 after administration of digitalis. The letters liave the sane significance as in Fir. 11.

Fia. 13.-Aortic Stenosis.-J. B., art. 51, admitted to Newcastle Infirmars under Dr Byrom Bramwell, 29th November 1878, suffering from anmmia and dropsy. There was a well-marked antic systolic murmur; the left ventricle was not hypertrophied. The pulse-tracing seems to show that the murmur was organic, and not henic.

Fsa. 14.-Mitial Regurgitation.-M. A. C., at. 16, admitted to Newcastle Infirmary under Dr Byrom Bramwell, 24th January 1878 , suffering from cough and shortness of breath, dating from an attack of rheumatic fever two months previously. Heart's action very rapid (120-130). The first sourd appeared to be reduplicated; a systolic murnur at the apex, audible when the heart became slower.

Fig. 15.-Weak Pulse.-R. R., a't. 17, admitted to Newcastle Infirmary under Dr Byrom Bramwell, 21st February 1878, suffering from idiopathic anemia. Died 12th April. There was a systolic (ana-mic) mitral nurmur. The pulse-tracing resembles that of nitral regurgitation (see Fig. 14). Tracing made 23d February.

Fur. 16.-Prngressive Pernicious Anrmia.-Same patient (see Fig. 15). Tracing taken 19th March. 'The artery is almost empty during diastole.

Fug. 17.-Dicrotism.-A. I., at. 32, admitted to Newcastle Infirmary under Dr Byrom Bramwell. 21st March 1878, with an enormous scrofulous kidney. There were occasional rigors. This tracing was made during a rigor, the temperature heing $100^{\circ} \mathrm{F}$. A driught of hot milk was administered, and the tracing, shown in Fig. 18, was taken. Tracing Fig. 19 a few minutes later.

lit. 18.-IIyperdicrotism. Fic. 19.- Hyperdicrotism.

Figure 5 .

Pulse tracings from Byron Bramwell, 'The examination of the pulse', Edinb. med. J., 1880, 26: p. 524. Particularly well demonstrated is the water hammer pulse of aortic regurgitation (Fig. 11), the plateau and anacrotic pulse of aortic stenosis (Fig. 13), and the hyperdicrotic pulse of infection (Fig. 18) 


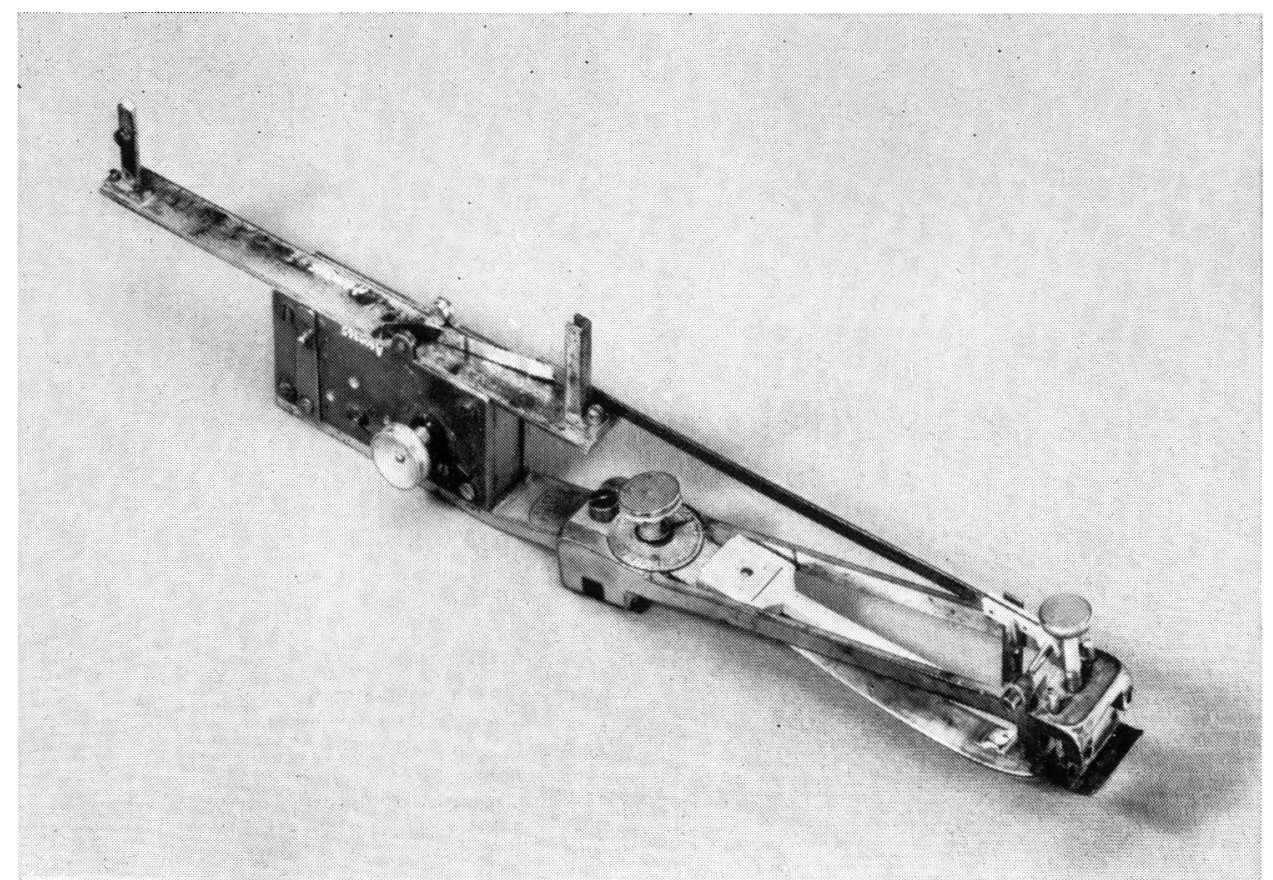

Figure 6.

Wellcome instrument II (see Appendix) shows the calibrated pressure screw and the screw at the distal end for raising the spring (see text).

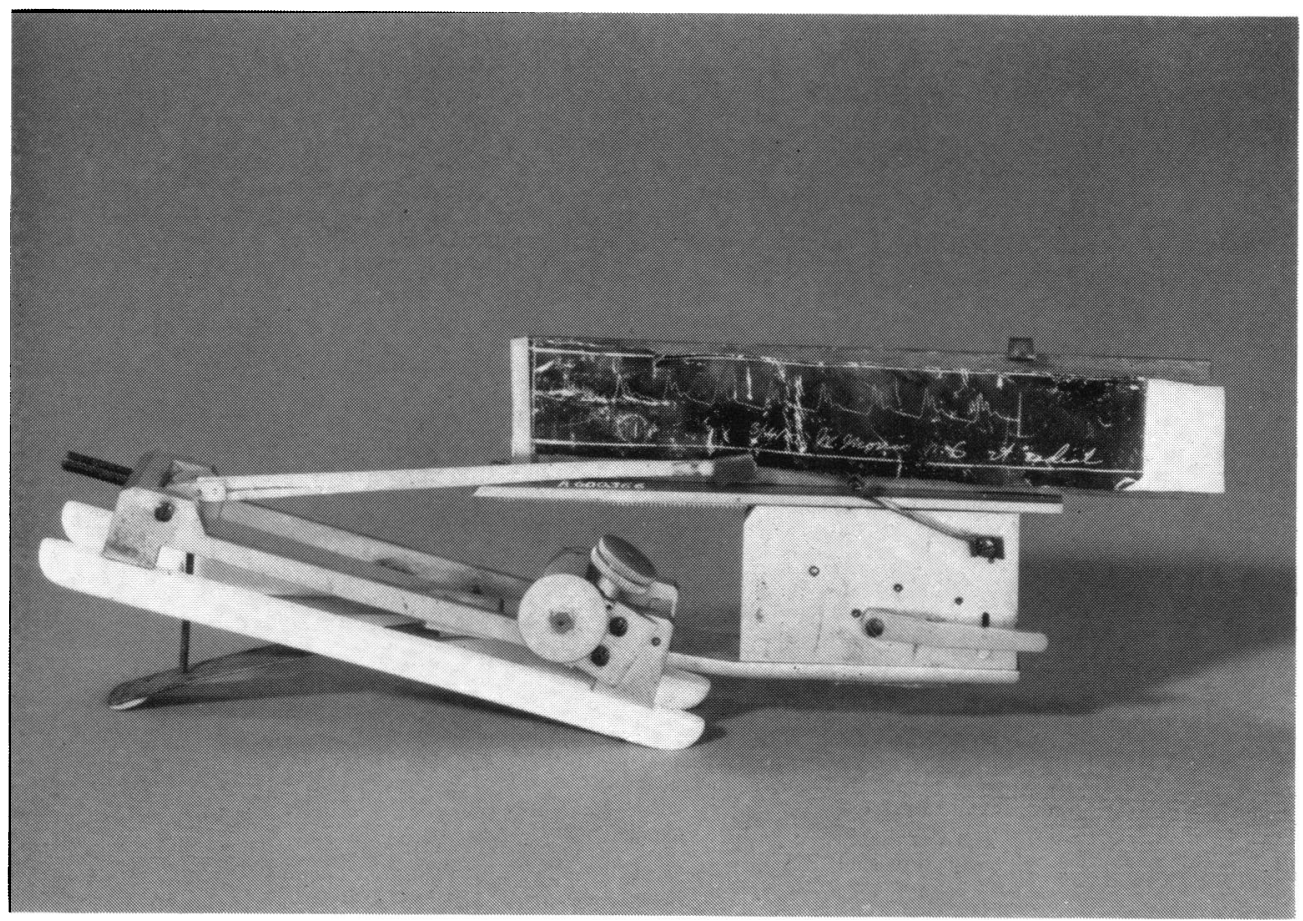

Figure 7.

Wellcome instrument IV (see Appendix). A Mahomed sphygmograph. 


\section{Short Articles}

in the eighteenth century, were resurrected by J. M. Poiseuille, who, in early nineteenthcentury Paris, calculated the force of the heart beat by observing the oscillation of mercury in a glass tube inserted into an artery. ${ }^{4}$ On to Poiseuille's device Carl Ludwig grafted the contemporary methods of graphic representation. The result was the famous kymograph. ${ }^{5}$

The first sphygmograph, that is an instrument applied to the unbroken skin, was constructed by Karl Vierordt (Fig. 1). ${ }^{6}$ Vierordt's instrument was large (168 cm long) and in order to prevent overshooting of the recording arm it required two heavily weighted levers to produce an undisturbed trace. Such an arrangement, Marey pointed out, converted the unequal rise and fall of the pulse into a symmetrical curve (Fig. 2). ${ }^{7}$

Frustrated by the limitations of Vierordt's model, Marey devised a simpler and far more accurate instrument, which he demonstrated in 1860 (Fig. 3). ${ }^{8}$ Étienne Jules Marey was born in Beaune in 1829 and in 1850 he entered the Paris School of Medicine. His doctoral thesis in 1860 was on the velocity of the pulse wave which he studied by pneumatic detectors. He discovered the refractory period of the heart and the eponymous law that relates heart rate and blood pressure inversely. Using the capillary electrometer, he recorded the first electrogram. ${ }^{\circ} \mathrm{He}$ also developed various instruments for investigating respiration and muscle contraction. Most remarkable was his use of cinematographic techniques in the 1870 s and 1880 s for the study of animal motion. ${ }^{10}$

Marey's sphygmographs were generally made of brass and secured to the wrist with a laced bandage. The interior (Fig. 4) consists of a flexible steel spring I which descends obliquely and is covered at its extremity by a plate of ivory $\mathbf{K}$. This plate rests on the radial artery. The movement is transmitted to the light wooden recording arm AA through a brass lever BE which has a knife edge at D and its centre of movement at $\mathrm{E}$. It is traversed by a vertical screw $\mathrm{T}$, the extremity of which, $\mathrm{N}$, rests on the plate. This screw varies the distance between the recording lever and the spring. A small spring $Y$ prevents erratic movement of the recording arm. The screw $\mathbf{P}$ regulates the amount of pressure exercised upon the artery by the spring. The extremity of the lever AA records the pulse on a moving strip of glazed paper. All the instruments are of this basic design, though No. 1 has the lever BE replaced by a rackwork device (see Appendix).

Marey's instrument immediately made apparent the asymmetrical nature of the pulse wave and its variation under a variety of physiological and pathological conditions (Fig. 5). Most notable was the appearance of the dicrotic notch in the descending stroke. Debate continued for some time as to whether this was an instrumental

4. M. Poiseuille, Recherches sur la force du coeur aortique, Paris, 1828.

s C. Ludwig, 'Beiträge zur Kenntniss des Einflusses der Respirationsbewegungen auf den Blutlauf im Aortensysteme', Müllers Archiv. Anat. Physiol. Wissensch. Med., 1847, pp. 242-302.

- Karl Vierordt, Die Lehre vom Arterienpuls, Braunschweig, F. Vieweg, 1855.

7 E. J. Marey, Physiologie médicale de la circulation du sang, Paris, Adrien Delahaye, 1863, p. 176.

B E. J. Marey, 'Recherches sur l'état de la circulation d'après les caractères du pouls fournis par le nouveau sphygmographe', J. Physiol. homme animaux, 1860, 3: 241-274.

' L. A. Geddes and H. E. Hoff, 'The capillary electrometer, the first graphic recorder of bioelectric signals', Arch. int. Hist. Sci., 1961, 14: 275-290.

${ }^{10}$ Anthony R. Michaelis, 'E. J. Marey-physiologist and first cinematographer', Med. Hist., 1966, 10: 201-203. 


\section{Short Articles}

artifact until Leonard Landois, by using his autosphygmogram or haemautogram, showed it to be a genuine component of the pulse. ${ }^{11}$

Marey's instrument was announced in Britain with a curt notice in the Lancet in 1860: "It may be doubted whether these instruments, though very ingenious, will ever prove actually useful in practice". ${ }^{12}$ The "ingenious device" commanded little attention except from two London physicians, Francis Anstie and J. BurdonSanderson, who were investigating the pulse in a variety of diseases in $1765 .{ }^{13}$ The history of a patient with axillary artery aneurism, under Anstie's care, was published in the Lancet in $1866 .{ }^{14}$ The radial pulses demonstrated graphically were, as they expected, quite dissimilar. Later in the same year the London group were horrified to discover that a Birmingham physician, Balthazar Foster, had rushed into print with a detailed essay on the use of the sphygmograph in disease. ${ }^{15}$ Charges of plagiarism were freely circulated. ${ }^{16}$ Foster's paper described Marey's original instrument without modification. He was concerned to point out its value in diagnosis, and illustrated this by displaying the traces found in a number of conditions. He illustrated the traces of hectic fever, senile arterial change, brachial and aortic aneurysms, aortic stenosis and incompetence, and mitral insufficiency. The pulse curves all show the expected features of these conditions even the hyperdicrotism of infection.

British physicians did not long remain satisfied with Marey's instrument and soon began suggesting modifications. The principal complaint was the inadequacy of the pressure screw $\mathbf{P}$, which altered the pressure that the spring exerted on the artery, and which was necessarily variable for the best trace to be obtained. The complaint was that the pressure was unknown, and could not therefore be duplicated on a subsequent occasion. Once more Foster was first in the field with a modification. ${ }^{17}$ It consisted of a single circular scale below the screw to which a pointer was attached (Fig. 6).

The difficulty of varying the pressure by a known amount stimulated the ingenuity of Anstie and Burdon-Sanderson, who adopted the principle of fixing the pressure of the centre button at $300 \mathrm{~g}$ and added to the distal end of the instrument a screw which would raise and lower the free end of the spring by a measured amount (Fig. 6). ${ }^{18}$ They also introduced the use of smoked glass instead of paper.

The most original investigator to use the Marey sphygmograph in Britain was undoubtedly Frederick Mahomed (1849-1884), who entered Guy's Hospital Medical School as a student in $1869 .{ }^{19} \mathrm{He}$ modified Marey's sphygmograph whilst still a

${ }^{11}$ Leonard Landois, 'Häemautographie', Pflügers Archiv, 1874, 9: 71-72.

12 Lancet, 1860 , i: 435.

13 Ibid., 1865, ii: 599.

14 Ibid., 1866, i: 176.

${ }^{16}$ Balthazar W. Foster, 'On the use of the sphygmograph in the investigation of disease', Br. med.J., 1866 , i: 275-278, 330-333.

10 Lancet, 1866, i: 579. Br. med. J., 1866, ii: 41.

${ }^{17}$ Balthazar W. Foster, 'Note on the regulation of the pressure on the artery in the application of the sphygmograph', Brit. for. med.-chir. Rev., 1867, 40: 240-242.

${ }_{18}$ Francis E. Anstie, 'On certain modifications of Marey's sphygmograph', Lancet, 1868, i: 783.

10 See Alfred P. Fishman and Dickenson W. Richards, Circulation of the blood: men and ideas, New York, Oxford University Press, 1964, pp. 497-502. 


\section{Short Articles}

student, and published his first investigations in 1872, the year in which he qualified. ${ }^{20}$ Mahomed's modification was once again of the pressure screw. In place of the original screw he placed over the centre of the spring a vertical eccentric turned by a graduated screw (Fig. 7). Mahomed also replaced the side wires, with which Marey's instrument was attached to the arm, with ivory bars. Mahomed's sphygmograph was undoubtedly the most popular modification of the original instrument. Five of the Wellcome instruments are of this type, and it is the instrument most frequently illustrated in catalogues.

Using the sphygmograph in the study of Bright's disease, Mahomed made various systematic estimations of the tension of the pulse in ounces, particularly in patients who were developing acute nephritis following scarlet fever. In other words he was recording the blood pressure. ${ }^{21} \mathrm{He}$ discovered the raised arterial tension that occurs before the proteinuria of Bright's disease. In another series of papers he correlated the raised tension with many of the post-mortem changes attributable today to essential hypertension. ${ }^{22}$ He regarded them as "Bright's disease without albuminuria."

The Marey sphygmograph remained in Britain a highly specialized tool to which most practitioners were indifferent. As Mahomed pointed out: "By far the largest number of our profession have continued in partial ignorance of its existence and completely so as to its clinical usage". ${ }^{23}$ Apart from Mahomed's own work, the sphygmograph received limited notice, although occasionally a clinician would encourage his colleagues to make use of it. ${ }^{24}$ It was finally eclipsed in the early $1880 \mathrm{~s}$ when R. E. Dudgeon introduced a more convenient model. ${ }^{25}$

The reception of the sphygmograph raises some interesting questions about the relationship of technology and medicine in the nineteenth century: "Despite great expectations and extravagant interpretations the new records at first added little knowledge beyond that which had already been gained by mere palpation or inspection of the arterial pulse". ${ }^{26}$ This in fact was well recognized by many clinicians in the late nineteenth century. A typical text on diagnosis could state that "as yet it has not done much to add to our knowledge of the diagnosis of cardiac diseases". ${ }^{27}$ In truth it was the passion of a few specialists. The technique was difficult to master, and attention was directed almost entirely to the shape and amplitude of the tracings. Rate and rhythm were largely ignored until the new discoveries concerning arrhythmia were made at the turn of the century. It is also now apparent that many of the tracings contain artifacts due to the method itself. The technique did, however, represent various conditions very vividly, notably organic heart disease (Fig. 5).

${ }^{20}$ F. A. Mahomed, 'The physiology and clinical use of the sphygmograph', Med. Times Gaz., 1872, i: $62-64$.

31 F. A. Mahomed, 'The aetiology of Bright's disease and the pre-albuminuric stage', Med. chir. Trans., 1874, 39: 187-228.

${ }^{22}$ F. A. Mahomed, 'Chronic Bright's disease without albuminuria', Guy's Hosp. Rep., 1881, 3rd ser. 25: 295.

${ }^{23}$ Mahomed, op. cit., note 20 above.

24 See for example, J. P. H. Boileau, 'The sphygmograph', Irish Hosp. Gaz., 1874, ii: 40; and Byron Bramwell, 'The examination of the pulse', Edinb. med. J., 1880, 26: 520-532.

${ }^{25}$ R. E. Dudgeon, The sphygmograph, London, Baillière, Tindall \& Cox, 1882.

26 Paul Dudley White, Heart disease, New York, Macmillan, 2nd ed., 1937, p. 105.

27 J. Milner Fothergill, Aids to diagnosis, London, Baillière, Tindall \& Cox, 1890, vol. 2, p. 36. 


\section{Short Articles}

The pursuit of a technique with such enthusiasm by some quarters of the medical profession in the nineteenth century, and their relatively unsuccessful encouragement of their colleagues to use it, has to be seen in the wider context of the status of medicine in Britain and the conception of physiology held by physicians. Experimental physiology only developed as a speciality in Britain in the 1870s. Prior to this the medical profession in Britain was characterized by an anatomical bias and a concern only with what was valuable in medical practice. ${ }^{28}$ In this context the Lancet's ambiguous reception of the instrument in 1860 is quite comprehensible. The device was not useful in practice and the description of it as "ingenious" was dismissive in its praise. By the later 1860s a small number of British physicians were directing their attention to the French and German experimental sciences. Significantly some of these physicians later became pure physiologists, notably Burdon-Sanderson. It was in this period that the first studies of the sphygmograph appeared. The eager reception by a minority of an instrument which was of relatively minor clinical value was a consequence of the emulation of continental models in the experimental clinical sciences; an emulation that perhaps led some disciples to overvalue the investigative potential of the instrument. The bulk of the profession however, remained uninterested in an instrument that added little to their diagnostic skill, and perhaps even challenged it. Interpreting the pulse, of course, was an art in which physicians took great pride.

\section{APPENDIX}

\section{MAREY SPHYGMOGRAPHS IN THE WELLCOME COLLECTION}

Marey's original instrument was made by Louis François Clement Breguet (Fig. 1). His firm was one of the leading manufacturers of instruments applicable to the physical sciences and the telegraph. He devised a self-recording, ink-writing, barometer. He seemingly continued to supply the motors for sphygmographs whose bodies were made elsewhere.

I. Marey design, though with transmission lever replaced by a rackwork device. ${ }^{29}$ Charles Verdin, Paris, c.1860. A.103280.

II. Incorporates modification by Foster and Anstie (see text). Breguet, Paris, c.1870. A.600 365. (see Fig. 2).

III. Mahomed type (see text). Krohne and Seseman, London, Motor by Breguet, c.1875. A.181855.

IV. Mahomed type. S. Maw \& Son, London, 1875. A. 600366.

V. Mahomed type. Breguet, c.1875. A.600 587.

VI. Mahomed type. Fine example with case containing drawers holding, side, paper, and tray for blackening paper. Krohne and Seseman. Motor by Breguet, c.1875. A.114212.

VII. Mahomed type. J. Weiss \& Son, c.1880. 1977-701.

${ }^{28}$ Richard D. French, 'Some problems and sources in the foundations of modern physiology in Great Britain', Hist. Sci., 1971, 10: 28-55.

${ }^{29}$ See A. H. Garrod, 'On sphygmography', J. Anat. Physiol., 1872, 6: 399-404. 